\title{
Mobility and Sustainability: A Computational Model of African Pastoralists
}

\author{
Takuto Sakamoto \\ ${ }^{1}$ Research Fellow of Japan Society for the Promotion of Science, Institute of Developing Economies, Japan \\ External Trade Organization (IDE-JETRO), Chiba, Japan \\ Correspondence: Takuto Sakamoto, Institute of Developing Economies, Japan External Trade Organization \\ (IDE-JETRO), Chiba, Japan. Tel: 81-43-299-9600. E-mail: takuto_sakamoto@ide.go.jp
}

Received: January 30, 2016

Accepted: February 15, 2016 Online Published: February 25, 2016

doi:10.5539/jms.v6n1p59

URL: http://dx.doi.org/10.5539/jms.v6n1p59

\begin{abstract}
This article offers a simple computational model of mobile pastoralists. Employing an agent-based modeling (ABM) approach, the model explicitly simulates the movement patterns of pastoralists and computes the resultant natural resource access for a landscape that shows the typically unpredictable dynamics of African rangeland ecology. Extensive simulations reveal a striking level of efficiency in the exploitation of resource endowments that mobile pastoralists can achieve in otherwise inhospitable environments. The simulations also illuminate the serious welfare consequences of the disruption of pastoral mobility under tight land constraints. These quantitative results are consistent with the rich qualitative evidence from the empirical literature on African pastoralism. Moreover, the article reports on several sets of 'policy experiments' that evaluate the effect of rangeland interventions on the mobility and livelihoods of pastoralists. These endeavors will pave the way for empirically richer and more policy-relevant analyses of dryland pastoralism.
\end{abstract}

Keywords: Africa, agent-based modeling, arid and semi-arid lands, mobility, pastoralism

\section{Introduction}

Managing variability in natural resource supply has been a major challenge for human societies in different places. For example, global agricultural production, even with contemporary technological advancement, entails a substantial amount of crop yield variability, which is largely due to climate variations (Kahsay \& Hansen, 2016; Ray, Gerber, MacDonald, \& West, 2015; Urban, Roberts, Schlenker, \& Lobell, 2012; Wheeler \& von Braun, 2013). The recent surge in demand for biofuel has made such production variability even more pronounced, as several studies on inter-annual variations in corn stover supply for the US suggest (Golecha \& Gan, 2016; Thompson, Meyer, \& Westhoff, 2009). Thus, the challenges posed by the variability in resource availability are broadly observed and have significant implications for global food and energy security.

This article concerns a similar challenge observed in yet another context: nomadic pastoralism practiced in arid and semi-arid lands (ASALs). ASALs cover approximately a third of the Earth's terrestrial surface (Food and Agriculture Organization [FAO], 2016). Because ASALs have typically low and unpredictable rainfall levels, the availability of natural resources such as vegetation or water is spatially patchy and temporally variable. Nomadic pastoralists inhabit these harsh environments. In Africa alone, where ASALs occupy approximately $40 \%$ of the surface, an estimated 268 million people rely more or less on a pastoral livelihood (African Union [AU], 2010). The key to their survival in inhospitable ASALs is mobility; nomadic pastoralists constantly move around extensive spaces with their livestock (camels, cattle, goats, sheep) and exploit spatially and temporally variable resources through the grazing of the livestock.

Pastoral mobility is a direct product of the long-term adaptation of pastoralists to the unpredictable ecological dynamics of ASALs. In recent years, however, this adaptive capability has been significantly challenged. Among various risks and threats faced by pastoralists, the most serious one is an increasingly intense trend toward land competition and deprivation, and its direct impingement on pastoral resource access and use (Boone, 2014; Lund, 2008). In Africa, for example, processes as different as state territorial control, agricultural development, wildlife conservation and oil drilling have been converging to bring about a significant level of displacement of pastoral communities (Galaty, 2013). The consequences can be quite serious; from bloody armed conflicts over 
increasingly scarce resources to the starvation of millions of people with a single instance of drought (e.g., the East Africa Drought in 2011-2012).

Against this backdrop, this article offers a simple computational model of pastoral mobility that can be an effective tool for understanding the sustainability of pastoralism in ASALs. The focus here is on natural resource access that mobile pastoralists can achieve under varying degrees of land use constraints. The main methodological approach is agent-based modeling (ABM). ABM represents a given social system and its dynamics by explicitly modeling the behavior and interactions of the component agents that share a common environment (Axelrod, 1997; Helbing, 2012; Sayama, 2015). Employing this approach, the model presented here simulates the complex movement patterns of pastoralists and computes the resultant resource access for a landscape that shows the typical 'non-equilibrium' dynamics of African rangeland ecology (Behnke, Scoones, \& Kerven, 1993; Ellis \& Swift, 1988; Oba, Stenseth, \& Lusigi, 2000). This model's behavior is then examined in different parametric settings, and the results are compared with the rich, but often disparate, empirical observations found in the previous literature on African pastoralism. The article also reports on several sets of 'policy experiments' concerning the land access of pastoralists - simulations that evaluate the effects of various rangeland interventions (e.g., land division, land expropriation) on the mobility and livelihoods of pastoralists.

The model of pastoral mobility presented here can contribute significantly to the literature on pastoralism. In the long history of this literature, mobility has always been a focus, especially among anthropologists (e.g., Baxter, 1972; Evans-Pritchard, 1940), but its importance for pastoralism in ASALs was not easily recognized in a wider community of researchers and practitioners, at least until the late 1980s. Several decades of outright failures of rangeland interventions in African drylands, such as group ranches and settlement schemes that seriously hampered pastoral movements, finally produced this recognition (Niamir-Fuller, 1999; Oba et al., 2000; Sandford, 1983; Scoones, 1994; Scoones \& Graham, 1994). A new generation of range ecologists who faced the uncertain and unstable nature (non-equilibrium dynamics) of the dryland ecology strongly promoted this trend by providing solid theoretical rationales for pastoral mobility (Behnke et al., 1993; Ellis \& Swift, 1988; Mace, 1991; Oba, Weladji, Lusigi, \& Stenseth, 2003).

With the growing appreciation of pastoral mobility, efforts toward data collection on this aspect of pastoralism have been accelerating. From daily herding around a temporary camping site to seasonal movements between ecological zones, pastoralists move on several different spatial and temporal scales. These movements have long been the object of detailed description among anthropologists and geographers (e.g., Bassett, 1986; Niamir-Fuller, 1999; Sato, 1980; Stenning, 1957). In addition to these studies, there is now a growing body of research that extensively utilizes advanced technologies such as satellite imagery and GPS to track the movements of pastoralists and their livestock (Adriansen \& Nielsen, 2005; Butt, 2010; Degteva \& Nellemann, 2013; Ermon et al., 2015; Moritz et al., 2010; Pickup \& Chewings, 1988; Sulieman \& Ahmed, 2013; Turner \& Hiernaux, 2002).

Despite the growing appreciation of mobility and the increasing volume of data, however, the progress in the literature has been seriously constrained in one important respect: there are few theoretical models that explicitly address pastoral mobility (see Dyson-Hudson \& Smith, 1978; Ermon et al., 2015; Moritz et al., 2015 for relevant works). There is a distinct lack of behavioral models of pastoralists that can generate coherent explanations and understanding of the various empirical observations and insights obtained in the literature. This is especially true for movements at relatively large spatio-temporal scales, such as seasonal transhumance (see Coppolillo, 2000; 2001 for a formal model of daily herding and grazing); these are the types of movements that can be most directly affected by the recent intensification of land competition and deprivation.

Without an adequate theoretical model that directly accounts for pastoralist movements at these scales, it will remain difficult to exactly determine the extent to which pastoralists can exploit variable resource endowments over extensive space in an extended period of time. This difficulty renders any rigorous assessment of the sustainability of pastoralism virtually impossible. The present study attempts to provide a first step in bridging this critical gap in the existing literature.

\section{Methods}

\subsection{Agent-Based Modeling (ABM) Approach}

One possible reason for the theoretical paucity mentioned above is a substantial amount of complexity involved in pastoral mobility. Pastoralists 'track' unpredictably changing landscapes in pursuit of grazing resources for their livestock (Sandford, 1983). In this process, pastoralists interact with each other as well as with other neighbors (e.g., farmers, traders, state agents) by mutually raiding, negotiating, trading, sharing and/or avoiding. Each movement made by each group of herders is a product of these strong spatial interactions. Hence, a 
modeling exercise can easily become too complex to enable a meaningful understanding of the subject at hand, as some of the preceding simulation models of pastoralists illustrate (Boone, 2005; Boone \& BurnSilver, 2002; Thornton, BurnSilver, Boone, \& Galvin, 2006). ABM, which is employed here, might not solve this problem, but it makes the problem methodologically manageable.

ABM has remained underutilized in the research on dryland pastoralism. Nevertheless, as several recent studies have shown (MacOpiyo, 2005; Moritz et al., 2015), this method can be fruitfully applied to the direct modeling of spatial behavior and interactions of pastoralists. Specifically, ABM can be a useful and effective tool for studying pastoral mobility for the following reasons. First, it can easily incorporate spatial heterogeneity and temporal dynamics, both of which are essential components of dryland ecology, into a model environment. Second, its bottom-up approach to modeling social and ecological phenomena, which typically formalizes local interactions among agents and then derives their collective consequences, naturally fits with the empirical literature characterized by a rich accumulation of local-level descriptions by ethnographers and ecologists. Third, it enables investigation of the effects of various factors and interventions, including counterfactual ones, on pastoral movement and resource access in a systematic way that empirical observation alone could not easily support.

\subsection{Modeling ASAL Ecology}

The model consists of two parts: a spatial environment (hereafter called ENV) and mutually interacting pastoral agents (NOMADs). ENV is a two-dimensional grid space representing a certain tract of ASALs. It has a heterogeneous spatial distribution of grazing resources that dynamically changes according to some stochastic rule. Rather than pursuing too much realism at this stage, ENV here reflects somewhat stylized but still realistic settings borrowed from the 'West African Nomads Game', well-crafted gaming material designed for geography education (Rice, 1975). In this game, students play the roles of Fulani pastoralists in northern Nigeria. The players move with their cattle on a monthly basis in response to seasonal changes in a model dryland landscape. ENV emulates the ecological dynamics of this landscape; NOMAD agents replace the human players. The model is coded in Python 2.7.5. The source code is downloadable from Bitbucket (https://bitbucket.org/ takutos/pastoralabm/).

As Figure 1 depicts, ENV in this case consists of 342 grid cells (19 rows; 18 columns). Although Rice did not mention an exact geographical correspondence between his gaming material and actual northern Nigeria, from what can be read on the original worksheet, the size of a cell is roughly estimated to be approximately $20 \mathrm{~km}$ along each axis.

\begin{tabular}{|l|l|l|l|l|l|l|l|l|l|l|l|l|l|l|l|l|l|}
\hline 2 & 2 & 2 & 2 & 2 & 0 & 2 & 2 & 2 & 2 & 2 & 2 & 2 & 2 & 2 & 2 & 2 & 2 \\
\hline 0 & 2 & 2 & 2 & 2 & 0 & 0 & 0 & 2 & 2 & 2 & 2 & 2 & 2 & 2 & 2 & 2 & 2 \\
\hline 0 & 2 & 2 & 3 & 2 & 0 & 0 & 2 & 2 & 2 & 2 & 0 & 2 & 2 & 3 & 2 & 2 & 2 \\
\hline 0 & 0 & 2 & 2 & 2 & 0 & 0 & 2 & 2 & 3 & 2 & 0 & 0 & 2 & 2 & 2 & 2 & 0 \\
\hline 0 & 0 & 0 & 0 & 0 & 0 & 1 & 0 & 0 & 0 & 0 & 0 & 1 & 0 & 0 & 0 & 0 & 0 \\
\hline 0 & 0 & 0 & 0 & 0 & 3 & 1 & 0 & 0 & 0 & 0 & 0 & 0 & 1 & 1 & 1 & 0 & 0 \\
\hline 0 & 0 & 0 & 0 & 0 & 1 & 1 & 0 & 0 & 0 & 0 & 0 & 0 & 1 & 3 & 0 & 0 & 0 \\
\hline 0 & 0 & 0 & 3 & 1 & 0 & 0 & 0 & 0 & 0 & 0 & 0 & 0 & 0 & 1 & 0 & 3 & 0 \\
\hline 0 & 3 & 0 & 1 & 3 & 0 & 3 & 0 & 0 & 0 & 0 & 3 & 0 & 0 & 1 & 0 & 0 & 3 \\
\hline 0 & 3 & 0 & 0 & 1 & 0 & 0 & 0 & 0 & 0 & 0 & 3 & 0 & 3 & 1 & 0 & 0 & 0 \\
\hline 0 & 0 & 0 & 0 & 1 & 0 & 0 & 0 & 0 & 0 & 0 & 0 & 0 & 1 & 0 & 0 & 0 & 0 \\
\hline 0 & 1 & 1 & 1 & 0 & 0 & 0 & 0 & 0 & 0 & 0 & 0 & 0 & 0 & 1 & 0 & 3 & 0 \\
\hline 0 & 0 & 3 & 1 & 0 & 3 & 0 & 0 & 3 & 0 & 0 & 0 & 0 & 0 & 0 & 1 & 0 & 1 \\
\hline 0 & 0 & 3 & 1 & 0 & 0 & 0 & 0 & 0 & 1 & 0 & 3 & 0 & 0 & 3 & 1 & 1 & 0 \\
\hline 3 & 0 & 0 & 0 & 1 & 3 & 0 & 0 & 1 & 3 & 0 & 0 & 0 & 0 & 1 & 0 & 3 & 3 \\
\hline 3 & 0 & 0 & 3 & 3 & 1 & 0 & 1 & 3 & 0 & 0 & 0 & 0 & 1 & 0 & 3 & 0 & 0 \\
\hline 3 & 0 & 0 & 3 & 3 & 0 & 1 & 0 & 3 & 0 & 0 & 3 & 1 & 0 & 3 & 3 & 0 & 0 \\
\hline 0 & 0 & 3 & 0 & 0 & 0 & 1 & 0 & 3 & 0 & 3 & 0 & 1 & 0 & 0 & 0 & 0 & 3 \\
\hline 3 & 0 & 3 & 0 & 0 & 0 & 1 & 3 & 0 & 0 & 0 & 1 & 0 & 0 & 3 & 0 & 3 & 0 \\
\hline
\end{tabular}

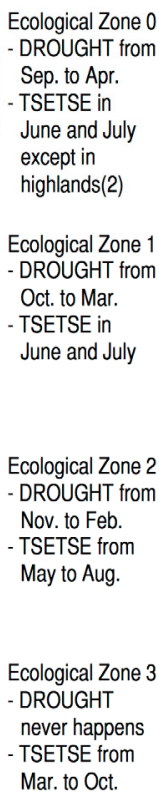

Figure 1. ENV landscape configuration and event occurrence 
This environment provides a single type of grazing resource for NOMAD agents, whose availability changes due to two types of events: DROUGHT and TSETSE. DROUGHT represents different levels of rainfall shortage in the dry season, whereas TSETSE represents a varying degree of spread of tsetse flies - the primary vectors of trypanosomes that can cause serious human as well as livestock diseases - in the rainy season. The occurrence of each of these events is both temporally and spatially controlled in the way mentioned in Figure 1. If the timing and the location are right for an event to occur, its realization and effect are determined according to the fixed probability distributions described in Table 1. As an example, suppose that an agent has moved to some grassland area (land class 0) in Ecological Zone 1. If that happens in January (or any other month from October to March), the agent can encounter a 'moderate' DROUGHT with a probability of $23 / 36$, in which case the available grazing resources would be reduced by $50 \%$ from a baseline level. Even worse, it can also suffer 'major' DROUGHT with a probability of $4 / 36$, in which case there would be no resource left for the agent. If, in contrast, the movement takes place in June rather than in January, the agent can escape any of these prospects, but it now has to face the stochastic occurrence of different varieties of TSETSE events, which would similarly reduce the amount of resources available to the agent. The baseline level of resource availability at each site is set to be the same (normalized to 1.0) anywhere other than the settlement sites (land class 3), which are assumed to offer nothing to NOMADs from the start.

Table 1. Effects and frequencies of drought and tsetse events

\begin{tabular}{lll}
\hline DROUGHT & Effect (reduction in resource availability) & Probability \\
\hline Major & $-50 \%$ (riverine areas(1)) & $4 / 36$ \\
Moderate & $-100 \%$ (otherwise) & $23 / 36$ \\
No drought & $-50 \%$ (except riverine areas(1)) & $9 / 36$ \\
\hline TSETSE & No effect & Probability \\
\hline Major & Effect (reduction in resource availability) & $4 / 36$ \\
Moderate & $-100 \%$ & $18 / 36$ \\
Minor & $-50 \%$ & $7 / 36$ \\
No tsetse & $-25 \%$ & $7 / 36$ \\
\hline
\end{tabular}

Overall, this spatio-temporal behavior of ENV captures the characteristic West African ecological dynamics, which vary along the north-south direction (from Sahelian to Sudanian to Guinean ecological zones) in a somewhat exaggerated fashion (Bassett \& Turner, 2007). As will be discussed later, ENV can be made more realistic with the use of empirical spatial data, such as satellite-derived vegetation data. Nevertheless, the present model has one clear advantage: free of the noise and other complicating factors these empirical data typically contain, the stylized environment makes it easier to see causal logic at work in the spatio-temporal behavior of NOMADs, thus fostering clear understanding of pastoral mobility and resource access.

\subsection{Modeling Mobile Pastoralists}

NOMAD agents, each of which represents a group of herders, move around in this variable, uncertain environment. They seek grazing resources for their livestock, whose existence is implicitly assumed in the model. For this purpose, each NOMAD plans a route of monthly movements over a year (ROUTE) and carries out this plan by visiting particular locations on ENV in the designated order. At some intervals of years, NOMADs adaptively update their ROUTEs in response to the amount of the resources actually obtained from ENV as well as the information on nearby resource availability that is occasionally collected during the course of their movement. Figure 2 depicts the basic flow of each NOMAD's behavior.

Formally, a ROUTE is a single cycle (denoted as $\rho$ ) connecting a series of two-dimensional integer coordinates (12 in total). Each coordinate denotes the location of a grid cell where the NOMAD concerned stays in each month of the year. The closed nature of a ROUTE emphasizes the empirical fact that many pastoralist groups have relatively stable transhumance cycles or, at least, vaguely conceived zones of movement, which are often formed around a more permanent base camp or settlement, such as a village or a town. As terms such as 'migratory drift' indicate (Stenning, 1957), these cycles or zones can change in the long run as pastoralists adapt to changing ecological and social circumstances. Similarly, NOMADs occasionally alter their ROUTEs in the way described below. ROUTEs for the first 'generation' of NOMADs are constructed randomly.

During the course of a year, each NOMAD implements its ROUTE faithfully: in each month, it visits the site designated in the ROUTE and obtains the grazing resources available there without any delay or perturbation. 
This is a theoretical assumption made for the sake of simplicity. Meanwhile, like many actual pastoralists (e.g., Niamir-Fuller, 1999; Sato, 1980), a NOMAD 'scouts' the surrounding landscape to collect information on local resource availability. This takes place with a specified probability per month (SCOUTING FREQUENCY, see Table 2 below), and if it happens, the NOMAD randomly selects one site within a specified distance (SCOUTING RANGE) from its camping site. The agent then records the coordinates of the site, the month of the scout, and the amount of the available grazing resources. If the agent has previously visited or scouted the same site in the same month, the gathered information is integrated with the preceding information, and the recorded resource availability becomes the time-mean value.

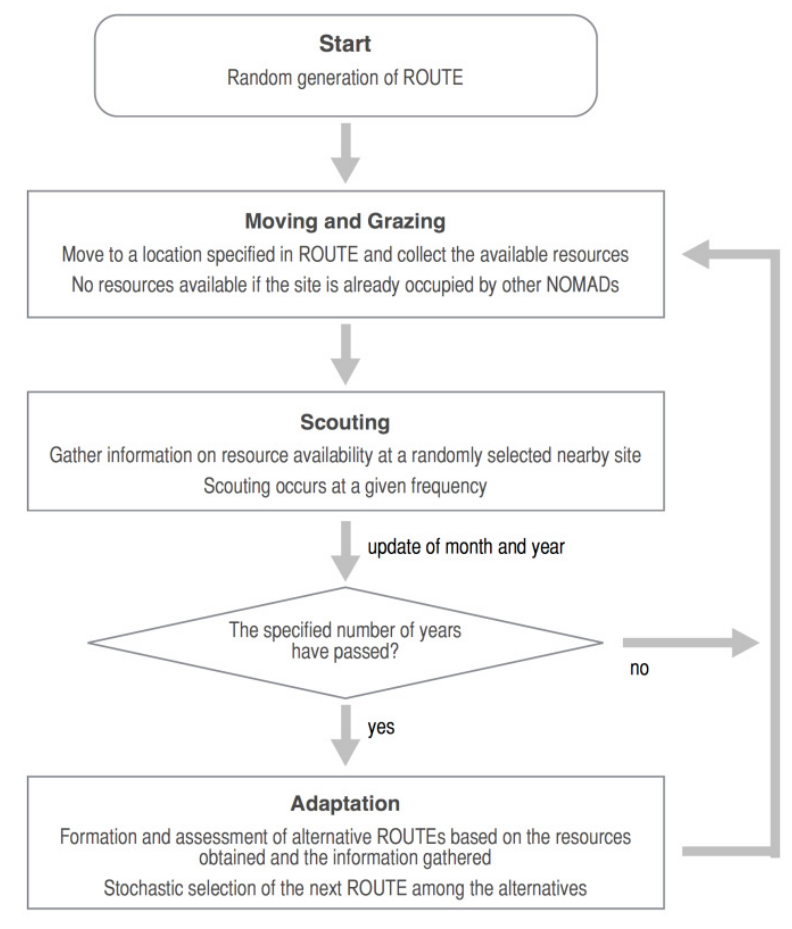

Figure 2. Behavioral rule of a NOMAD agent

Based on this information, a NOMAD renews its own ROUTE at specified intervals of years (INTERVALS OF ROUTE UPDATE). It considers the specified number of alternative yearly paths (NUMBER OF ALTERNATIVE ROUTES) along with the existing one that the agent has followed thus far. These alternatives are random combinations of the sites that the agent has already visited or scouted. For example, suppose that a NOMAD adopted a ROUTE $\rho_{1}$ in the preceding years, which dictated a yearly path $(3,3) \rightarrow(5,1) \rightarrow(2,3) \rightarrow(3$, $7) \rightarrow(4,8) \rightarrow(3,6) \rightarrow(2,7) \rightarrow(2,4) \rightarrow(3,3) \rightarrow(3,5) \rightarrow(4,4) \rightarrow(4,3)$ starting from January. Suppose also that, in the past, this NOMAD scouted a site $(4,2)$ in February and a site $(2,7)$ in October. Then, three alternative paths (i) $(3,3) \rightarrow(4,2) \rightarrow \ldots \rightarrow(3,5) \rightarrow(4,4) \rightarrow(4,3)$, (ii) $(3,3) \rightarrow(5,1) \rightarrow \ldots \rightarrow(2,7) \rightarrow(4,4) \rightarrow(4,3)$ and (iii) $(3,3) \rightarrow(4$, 2) $\rightarrow \ldots \rightarrow \underline{(2,7)} \rightarrow(4,4) \rightarrow(4,3)$ can be constructed from the existing path $\rho_{1}$ and the two scouted sites.

The agent assesses each of these paths by computing its 'potential'. Lower potential implies more favorable assessment and thus higher probability for the path to be adopted as the next ROUTE. Formally, the potential $H\left(\rho_{\mathrm{i}}\right)$ for the $\mathrm{i}$-th alternative path $\rho_{\mathrm{i}}$ is a linear combination of the (negative) expected availability of grazing resources and some costs incurred during the agent's movement along the path, as the following equation formalizes:

$$
H\left(\rho_{i}\right)=\alpha\left(-\sum_{m=1}^{12} R_{m}\left(\rho_{i}(m)\right)+\sum_{m=1}^{12} C\left(\rho_{i}(m), \rho_{i}(m+1)\right)\right)+\beta
$$

where $\rho_{\mathrm{i}}(\mathrm{m})$ denotes a site that $\rho_{\mathrm{i}}$ dictates the agent to visit in the $\mathrm{m}$-th month, the function $R_{m}$ returns the time-mean of grazing resources available at that site in the m-th month, and the function $C$ computes the movement cost incurred while the agent moves between two adjacent sites along $\rho_{\mathrm{i}}$. Note also that the cyclic 
nature of a ROUTE assumed here demands $\rho_{\mathrm{i}}(13)=\rho_{\mathrm{i}}(1)$. Lastly, $\alpha$ and $\beta$ are scaling parameters. In the following simulations, these are set to 0.00893 and 0.10714 , respectively. This combination of values gives the minimum zero potential to the 'ideal' state in which the agent always obtains the maximum amount of grazing resources (1.0 per month) without incurring any movement cost along the way.

Concerning the cost function $C$, there are diverse empirical observations about pastoralists' own perceptions of mobility (e.g., Adriansen, 2008; Baxter, 1972), so various functional forms for $C$ are conceivable. Here, $C$ is specified in the simplest possible way, focusing only on the most obvious limitations to pastoral mobility: physical and physiological constraints on human as well as livestock movement. Specifically, for each pair of adjacent sites along a given path $\rho_{\mathrm{i}}$, if the distance between the two sites exceeds a certain mobility threshold (MOVE RANGE), the agent suffers a huge 'penalty' (PENALTY TO MOVEMENT BEYOND RANGE). The overall movement cost of the path is a sum of these penalties, which effectively discourages physically unrealistic ROUTEs.

The stochastic selection of a new ROUTE occurs based on the potential values of the alternatives thus calculated. The probability $P\left(\rho_{\mathrm{i}}\right)$ that the agent will adopt an alternative path $\rho_{\mathrm{i}}$ as its next ROUTE is given by the following formula:

$$
P\left(\rho_{i}\right)=\frac{\exp \left(-H\left(\rho_{i}\right) / E\left(H\left(\rho_{1}\right)\right)\right)}{\sum_{j=1}^{N} \exp \left(-H\left(\rho_{j}\right) / E\left(H\left(\rho_{1}\right)\right)\right)}
$$

The summation in the denomination is taken over all the alternative paths ( $N$ in total) considered by the agent during the update. $E$ controls the amount of random perturbation (STOCHASTIC NOISE) applied to the agent's ROUTE selection. Its dependence on the potential of the current ROUTE $\left(\rho_{1}\right)$ allows a dynamic and flexible adaptation process: a NOMAD 'explores' a variety of alternatives in a trial-and-error fashion if the existing route has not been satisfactory, whereas the same agent begins to 'exploit' whatever path has turned out to be rewarding (Holland, 1992). Here, a simple functional form is assumed for $E$. The noise $E$ takes a minimum value $\left(1.0^{-5}\right.$ in the following simulations) whenever the potential $H$ hits the bottom $(0.0)$, whereas $E$ takes a maximum value $\left(1.0^{-2}\right)$ whenever $H$ reaches a certain high value (here set to be 1.0 ). The dependence is linear between these two extremes.

Finally, direct interactions between NOMADs happen whenever two or more agents stay at the same site in the same month. Then, the randomly selected 'first comer' takes all of the available resources, effectively dislodging the other agents; this is a somewhat crude assumption that is not always supported by empirical observations (see the next section). Moreover, following the original formulation of West African Nomads Game, whenever a NOMAD exploits a site, that site becomes 'degraded' and the grazing resources there remain unavailable (set to be 0.0 ) for the next three months. These rather exaggerated forms of interactions, along with other aspects of the model described above, overly simplify the diverse and complex nature of pastoralist behavior (see Homewood, 2008). Nevertheless, this minimal combination of simplified actions and interactions can capture some of the essential empirical properties of pastoral mobility and livelihoods.

\section{Results and Discussion}

This section reports and discusses simulation results that were obtained by running the model in different settings. Reflecting the interests posited at the beginning of this article, the simulation outputs discussed here are spatial movement patterns (as represented by ROUTEs) that NOMAD agents evolve over time as well as conditions of resource access among the agents that these patterns produce. Unless otherwise mentioned, the simulations reported below were conducted with the parameter values given in Table 2. The results show a certain degree of robustness against changes in these parameters.

Table 2. The common parameters and their values

\begin{tabular}{lr}
\hline INTERVALS OF ROUTE UPDATE (years) & 10 \\
MOVE RANGE (per month) & 5 \\
SCOUTING FREQUENCY (per month) & 0.1 \\
SCOUTING RANGE (from the camping site) & 5 \\
NUMBER OF ALTERNATIVE ROUTES (incl. current ROUTE) & 100 \\
PENALTY TO MOVEMENT BEYOND MOVE RANGE & 10 \\
STOCHASTIC NOISE & {$[0.00001,0.01]$} \\
\hline
\end{tabular}




\subsection{One NOMAD Model}

Given the structure of the model, the simplest possible setting is a scenario in which a single NOMAD is moving freely over the ENV. The land access is completely open to this agent without any competitor hindering its land use. Nothing other than its own physical limit (represented by MOVE RANGE in Table 2) constrains its movement. This is an utterly unrealistic situation but nevertheless offers a useful starting point for the theoretical understanding of pastoral mobility and resource access.

Figure 3 presents a snapshot of the model's typical behavior in such a scenario. It plots successive locations of monthly 'camping sites' specified in the NOMD's ROUTE, with each circled number denoting the corresponding staying month. Starting from an initial ROUTE that consists of randomly chosen sites, the model has evolved a rather clear pattern of north-south transhumant movement across different ecological zones. Specifically, the NOMAD avoids tsetse flies by staying around highland areas in the north during the rainy season, and it flees impending droughts into more humid southern areas as the dry season progresses. These features are highly consistent with the widely recorded movement patterns of Fulani herdsmen in West Africa (Bassett, 1986; Stenning, 1957; Turner, 1999; Bassett \& Turner, 2007).

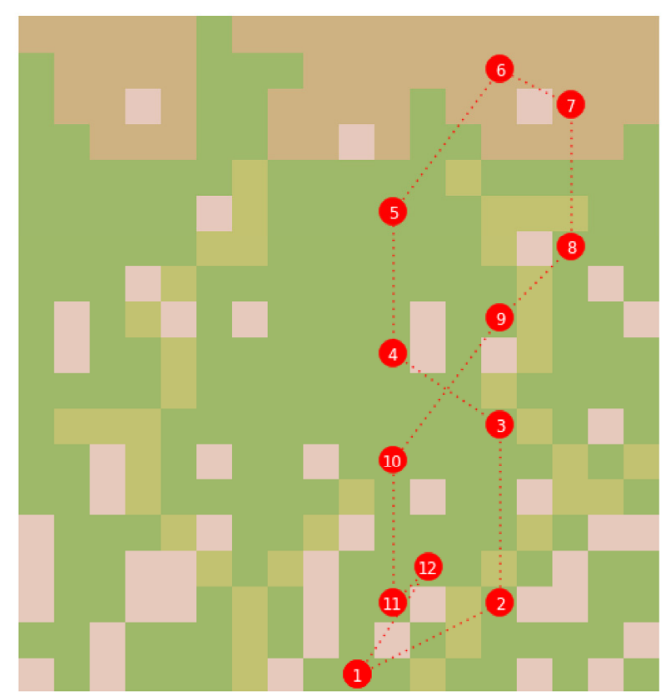

Figure 3. A snapshot of a simulation run

Note. One NOMAD case, taken after 5000 updates of ROUTE.

Although the particular snapshot in Figure 3 was taken after 5000 updates of ROUTE, it does not generally take long to see the first emergence of such a pattern of movement. Most of the time, the 'relaxation' occurred fairly quickly, after several hundreds of updates at most. Thereafter, the overall pattern of the north-south transhumance basically remained, although the exact locations of composite sites constantly changed and an abrupt alteration of ROUTE occasionally occurred due to the stochastic elements incorporated in the model. Moreover, this dynamically stable pattern of movement was consistently observed across different simulation runs seeded with different series of random numbers.

Figure 4 captures the model's dynamics in the one-NOMAD scenario from a different angle. The graph depicts the time series of a mean amount of resources obtained during a period between two consecutive updates of ROUTE, denoted here as 'Generation', which, given the 10-year update intervals specified in Table 2, amounts to 120 months. The graph suggests that despite suffering occasional fluctuations of resource availability, the NOMAD managed to access a relatively large amount of grazing resources by tracking the changing environment along the north-south path. 


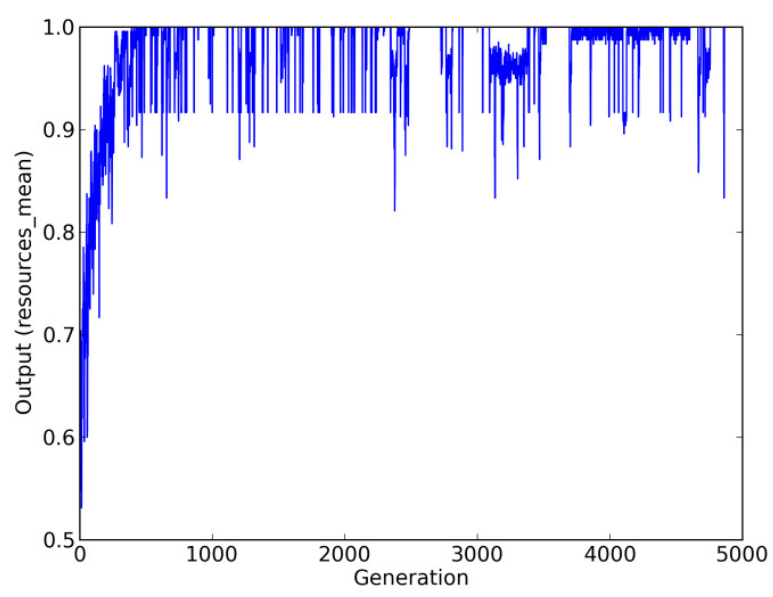

Figure 4. Time-series of mean grazed resources

This becomes even clearer when the samples are binned and rearranged as a histogram as in the blue graph in Figure 5. Here, the samples obtained from the first 1000 generations are removed because of the generally unsettled nature of adaptation process in the early part of a simulation run. The graph shows that, at a frequency as high as $73.55 \%$, the NOMAD was able to access the maximum amount of resources available (1.0) during all the months in a generation, avoiding any misfortune that DROUGHT and TSETSE could pose to it. The mean value of the distribution of obtained resources reaches 0.989 (standard deviation: 0.024), meaning that this agent, on average, suffered only a $1.1 \%$ loss of efficiency during the last 4000 generations of the run. The maximum loss per generation that the same agent experienced in the same period amounted to approximately $18 \%$. This is substantial damage, but, as the histogram indicates, such misfortune occurred only rarely.

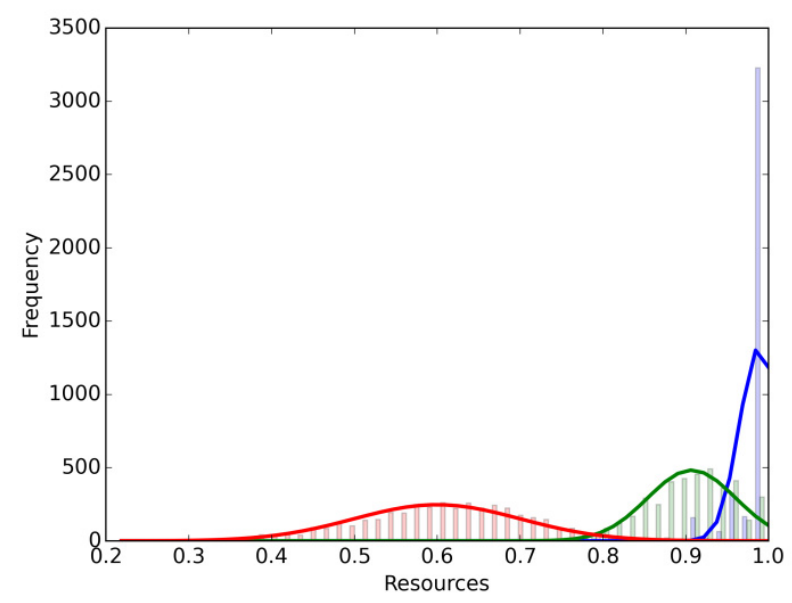

Figure 5. Comparison of frequency distributions of mean grazed resources

Note. blue: performance of a 'regular' NOMAD; green: its performance without the knowledge inheritance rule; red: performance of randomly moving agents. First 1000 samples were omitted in the first two cases. The curves indicate fitted Gaussian distributions.

The other two histograms displayed in Figure 5 suggest possible contributing factors involved in this impressive performance shown by the NOMAD agent. First, the red graph reveals that the high performance is a direct product of the agent's constant adaptation to the variability and uncertainty of the surrounding landscapes. The graph illustrates the frequency distribution of the time-means of resources obtained by 4000 unadaptive agents. A ROUTE of each agent here was randomly generated and only constrained by the mobility limit of 5.0. The mean (averaged over 4000 agents) of this distribution is 0.601 (standard deviation: 0.101). A quick comparison with 
the blue graph in the same figure confirms that the movement pattern that the NOMAD evolved brought about marked improvement in its performance in living in ASALs.

These quantitative results provide strong theoretical support for the 'mobility paradigm' that has been developing for the past several decades (Niamir-Fuller, 1999). At the same time, something more than mere mobility is involved here. The green histogram in Figure 5 illuminates this. This time, the NOMAD adapts its ROUTE constantly as it did before, but the knowledge about the surrounding landscapes that the agent has gained while moving and scouting is never inherited or accumulated beyond one generation (120 months). In other words, the NOMAD now has to choose its next ROUTE solely based on the information that it has gathered after the previous update event. As the figure illustrates, this change causes a noticeable downturn in the agent's performance, with access to resources becoming both more limited (sample mean: 0.907) and more unreliable (standard deviation: 0.053). This result implies that extensive ecological knowledge and its inheritance constitute a major component of pastoral adaptability, again corroborating the wide array of empirical observations found in the literature (Oba \& Kaitira, 2006; Sato, 1980; Schareika, 2003; Sulieman \& Ahmed, 2013).

\subsection{Introducing Interactions among NOMADs}

Departing from the single-agent setting, this sub-section examines the possible effects of introducing multiple agents into ENV. Given the exclusive nature of local interactions assumed in the model, increasing the number of NOMADs generally implies increasing the pressure of land competition. This alteration of settings adds new dimensions to the overall behavior of the model.

Figure 6 shows snapshots of two different simulation runs: one with two agents and the other with ten. The familiar pattern of north-south transhumance is still visible in both panels, indicating that the tendency for a NOMAD to adaptively develop this pattern is highly persistent. However, a certain degree of disruption of the pattern can be observed in the right panel. Without going deeply into the quantitative details, this disruption manifests in (1) a decreasing range of movement, especially along the north-south direction, and (2) a decreasing degree of synchronization among moving directions of different agents. These aspects become even more pronounced as the number of NOMADs increases further.
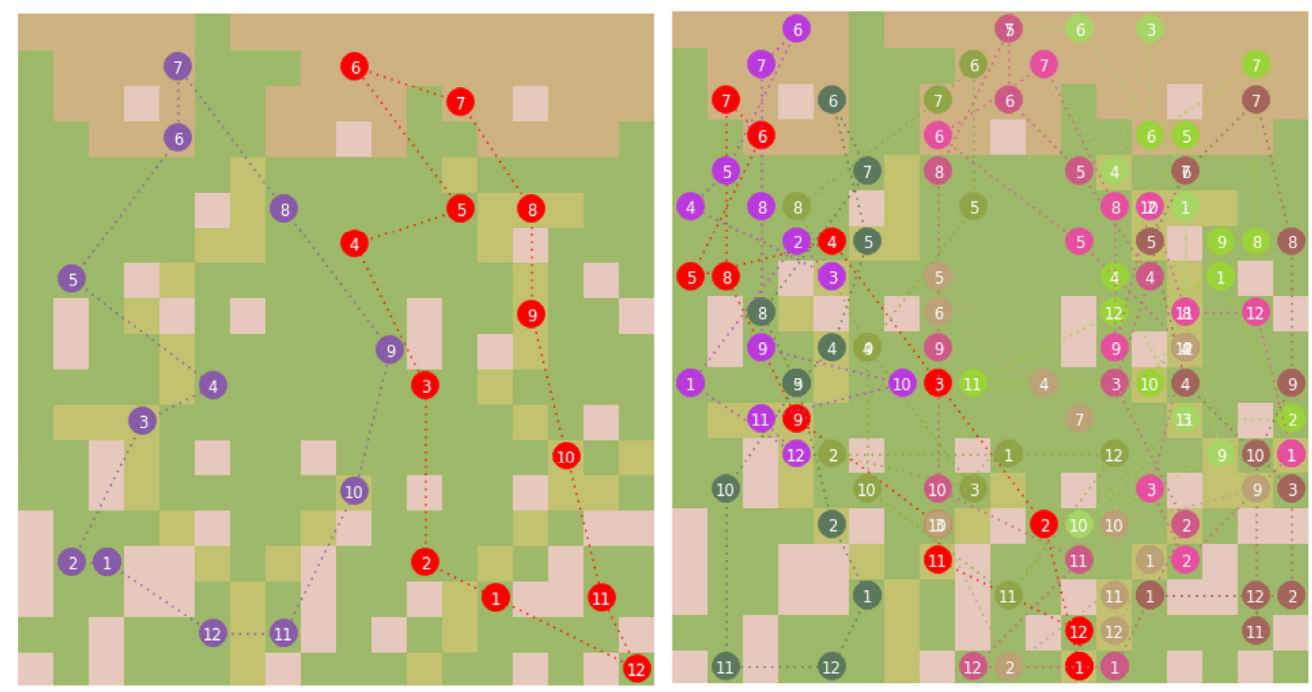

Figure 6. Snapshots of simulation runs

Note. left: two-NOMAD case after 4500 updates; right: ten-NOMAD case after 5000 updates.

The disrupted mobility has significant welfare implications. Figure 7 illustrates the generally worsening resource access experienced by NOMADs in these situations. Here, using different series of random numbers, adaptation dynamics for 5000 generations of NOMADs were replicated ten times at each level of NOMAD population. Relevant statistics summarizing each run of the simulations, which were again computed from the outputs obtained in the last 4000 generations, were averaged over these ten runs. 


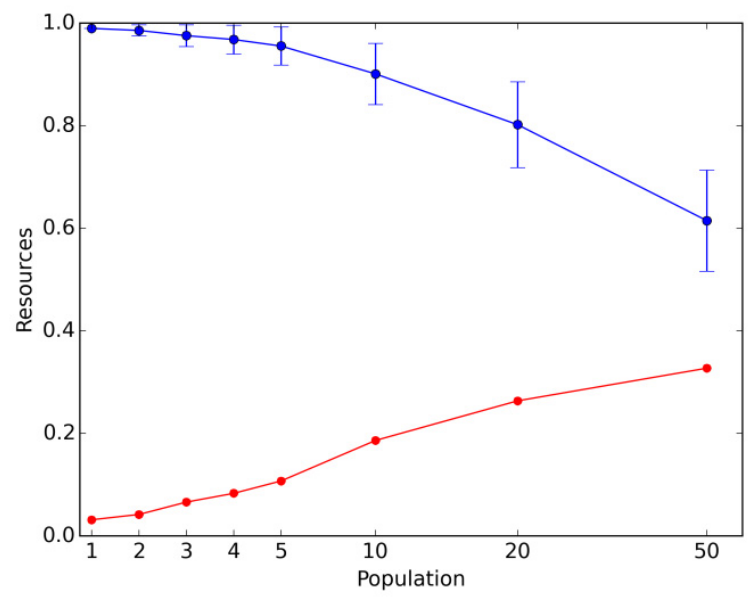

Figure 7. Comparison of resource statistics among different population settings

Note. blue: mean grazed resources (an error bar indicates a standard deviation among NOMADs); red: monthly standard deviations of grazed resources. Computed from the data obtained during 5000 ROUTE updates in ten runs at each population level. First 1000 samples were omitted.

As the blue line graph in the figure depicts, the overall level of resource access, as measured by the mean amount of obtained resources that are averaged over both time and agents, steadily declines as NOMADs begin to suffer from increasingly packed landscapes. Moreover, this decline has a serious distributional aspect: a widening gap among NOMADs with regard to resource access. This is reflected in the steady rise in the length of an error bar, which denotes the standard deviation of obtained resources among all agents. In fact, the further analysis suggests some form of stratification of NOMAD agents: poorly performing NOMADs suffer the most from the increasing pressure of land shortage, whereas well-placed NOMADs manage to contain possible loss to a certain degree.

Lastly, the red line graph in Figure 7 displays yet another consequence of the increased interactions among agents. Here, the model's behavior at each level of the population is summarized by the monthly standard deviation of resources obtained by a NOMAD over a year, which is then averaged over time and agents. This indicator, denoting the fluctuation of resource availability over time, can usefully be considered the overall vulnerability of NOMADs to the unpredictable ecological dynamics of ENV. As the figure indicates, increasing the population tends to amplify this vulnerability.

These analyses clearly suggest that a heightened level of land competition among a significant number of NOMADs, through the disruption of their mobility, can lead to overall deterioration in resource access, widening inequality of this access among the agents, and increased vulnerability of the agents to the unpredictability of drylands. These negative effects depend on various specifications of the model, including the somewhat crude assumption - 'first-come, first-served' - about agent interactions. This assumption is not always true. Rather, the nature of relationships among pastoralist groups is mostly reciprocal and often highly complex (e.g., Spencer, 1973). Nevertheless, the unfavorable prospects described above cannot easily be disregarded because they capture the widely documented aspects of pastoral societies in the current world. In fact, poverty, inequality and vulnerability, along with various other sources of risk, have frequently been associated with reduced means of pastoral livelihoods, such as the disrupted mobility (Catley \& Aklilu, 2013; Dong et al., 2011; Fratkin \& Roth, 2004; McPeak, Little, \& Doss, 2012; Opiyo, Wasonga, \& Nyangito, 2014; Scoones, 2013; Toth, 2015).

\subsection{Manipulating Institutional Settings}

Given these negative prospects, the next logical step might be to seek ways to ameliorate or avoid them. Although various 'levers' for affecting the model's dynamics are conceivable, an obvious option is to find a proper institutional setting that induces agent interactions toward a more desirable direction. In the context of African pastoralism, institutional matters have most often been discussed with regard to land ownership and land use in ASALs (Lane \& Moorehead, 1994; Moritz et al., 2013; Musembi \& Kameri-Mbote, 2013; Niamir-Fuller, 1999). As the first step toward a more comprehensive treatment of this subject, some of the standard (and often controversial) rangeland interventions are examined in the simulated drylands. 
Two broad types of rangeland interventions are considered: land division and land expropriation. So far, the land access in ENV has been governed by something similar to a universal 'open access' institution, in which any NOMAD can legitimately access and use resources anywhere. The land division changes this situation by dividing the land and assigning each tract to a particular NOMAD or a particular group of NOMADs for its exclusive use. This is a somewhat crude notion because, depending on the specific context, the resulting form of land tenure can become either private ownership or group ownership, such as a group ranch. The land expropriation, in contrast, takes some portion of the land away from NOMADs altogether for completely different land use. Again, depending on the specific context, it may be 'nationalization', 'agricultural encroachment', 'land grabbing', and so on.

Specifically, the following four variants of land division are introduced to the model: (1) 2-by-2 equal division of the ENV (denoted as ' $2 * 2$ '), (2) 3-by-3 equal division (' $3 * 3$ '), (3) 5-by-5 equal division (' $5 * 5$ '), and (4) division of the land into 4 areas along the north-south direction (' $1 * 4$ '). Each NOMAD is then associated with one of the areas so that the resulting agent distribution becomes as even as possible. A NOMAD cannot gain any resources outside its own assigned area. With the exception of these artificial treatments, simulation is conducted as before.

Figure 8 shows some of the results obtained when ten NOMADs interact with each other under each of the land division regimes. As in Figure 7, the summarizing statistics about resource access were averaged over ten runs in each case. Both the one-way ANOVA ( $\mathrm{N}=10$ in each set of samples; F-value: 226.56 in the case of mean resources, which implies an almost infinitesimal p-value) and non-parametric Kruskal-Wallis H-test (H-statistics: 46.70) strongly indicate that the difference in land division has a significant impact on resource availability to NOMADs. In particular, in the most sweeping ' $5 * 5$ ' case, resource access conspicuously worsens, and the inequality of access among the agents is obviously heightened. In fact, 2-independent-sample t-tests on the relevant statistics against the control case (without any land division) return extreme t-values, -17.23 for mean resources and 3.93 for standard deviation. In contrast, in the case of ' $1 * 4$ ' division, which still allows NOMADs to exploit a certain degree of ecological variability along the north-south direction, these negative effects are not so pronounced (t-value: -5.64 for mean resources, which still implies an very small p-value). All of these results suggest that the rangeland regime that disregards the underlying ecological dynamics can have serious consequences for pastoralists, a point made by scholars such as Scoones $(1995 ; 1999)$.

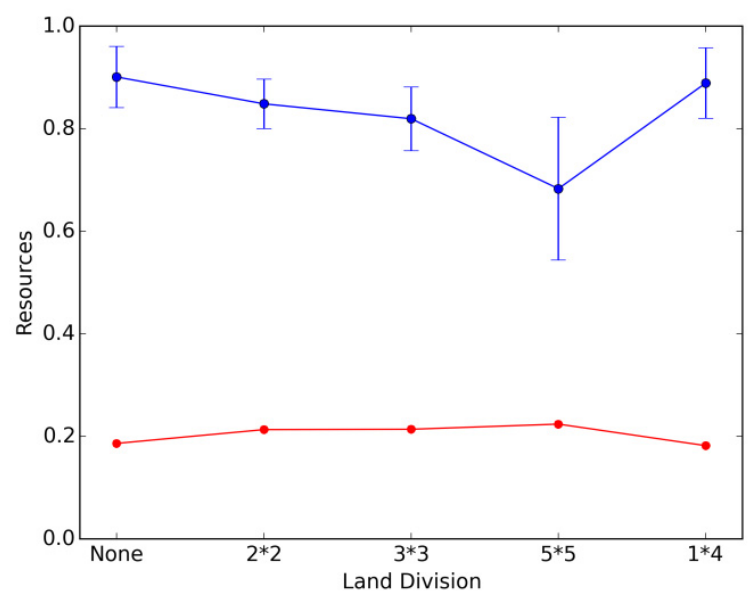

Figure 8. Comparison of different land division treatments (10-NOMAD setting)

Note. blue: mean grazed resources (an error bar indicates a standard deviation among NOMADs); red: monthly standard deviations of grazed resources. Computed in the same way as in Figure 7.

Regarding the land expropriation, simulations were conducted with the following five variants as treatments: (1) random confiscation of $30 \%$ of the entire space (342 sites), excluding the settlement areas ('Random'); (2) expropriation of all 40 sites belonging to riverine grasslands (land class: 1) ('River'); (3) expropriation of all 72 sites belonging to the most humid ecological zone 3 ('Zone3'); (4) expropriation of all 56 sites belonging to highlands (land class: 2) ('High'); (5) the same as (4) except that the highlands become open to NOMADs in two 
months (June and July) in the rainy season ('High-'). In the expropriated sites, a NOMAD cannot gain any resources.

Some of the results in the 10-NOMAD setting appear in Figure 9. Again, the one-way ANOVA (F-value: 329.01 for mean resources) and Kruskal-Wallis H-test (H-statistics: 48.85) strongly confirm the overall effects of the difference in land expropriation on various indicators of resource access. As the figure illustrates, different measures of land expropriation generally reduce the availability of resources to NOMADs, but the specific impact can vary considerably depending on which type of land is actually affected. For example, compared with the control case (without any land expropriation), the 'Zone3' treatment leads to the most marked reduction in the average amount of resources available ( $t$-value: -39.06 , which implies a near-infinitesimal $p$-value). In contrast, with regard to the inequality of access as measured by a standard deviation of resources, 'Random' can cause the most undesirable consequence (t-value: 19.11). Lastly, the sharp contrast between 'High' and 'High-' treatments (t-value: 30.97 for mean resources) reveals the critical importance of the temporal dimension of access for a viable rangeland regime.

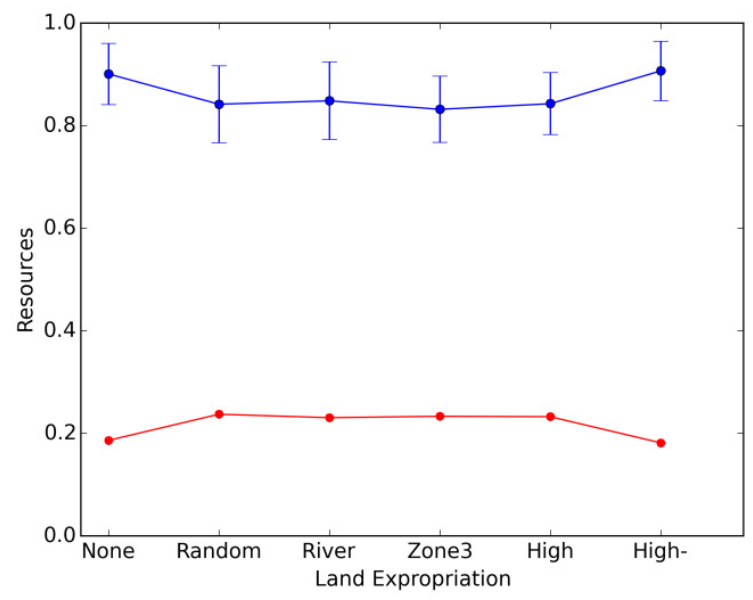

Figure 9. Comparison of different land expropriation treatments (10-NOMAD setting)

Note. blue: mean grazed resources (an error bar indicates a standard deviation among NOMADs); red: monthly standard deviations of grazed resources.

\section{Conclusions}

This article presents an agent-based model of pastoralist movement that attempts to advance theoretical understanding of this crucial component of dryland pastoralism. The model has a simple structure and simple behavioral rules, often greatly simplifying intricate and complex aspects of pastoral livelihood. Nevertheless, it retains some essential elements of actual pastoralist behavior, such as the adaptive adjustment of a movement pattern and the information gathering on local rangeland conditions.

Applied to stylized ASAL settings imported from gaming material for geography education, this model was able to generate a rich array of dynamics and patterns. Among others, the agents in the model adaptively developed a specific type of movement pattern that enabled them to exploit variable resource endowments in ASALs at a remarkable level of efficiency as long as the agent population remained sparse. The model also revealed serious welfare consequences of the disruption of this movement pattern under the condition of heightened population pressure and land use constraints. Along with other findings, such as the importance of ecological knowledge and its inheritance, these results are largely consistent with empirical observations and insights found in the preceding literature on pastoralism, especially those in the 'mobility paradigm'. Thus, the main contribution of this study is a theoretical one: a relatively simple computational model can neatly capture and quantitatively represent the observations made on different aspects of pastoral livelihoods in different parts of ASALs.

Moreover, the same model was shown to be fruitfully deployed for more practical, policy-oriented purposes. Manipulating institutional settings with regard to land access and use, some of the standard alternatives of rangeland intervention, such as land subdivision, were introduced to the model, and their effects were examined. These alternatives, which are formal and territorial in nature, have been harshly criticized and sometimes entirely 
discredited in the previous literature (Behnke, 1999; Scoones, 1999). Overall, the simulation results corroborated such assessments, but they also showed the complicated nature of policy effects, which depend on specific aspects of a given intervention such as the type and the location of the land affected by the policy. Moreover, the simulations illuminated the critical importance of the spatial variability and temporal dynamics of rangeland ecologies in mediating such effects. Considering these ecological aspects will be a first step toward workable rangeland policies and institutions.

Finally, the model, which is simple and stylized, can be improved and extended in various ways. For example, the model can incorporate stronger interactions between the agents and the environment through more explicit modeling of the former's rangeland management and the latter's responses to it (e.g., land degradation). It can also embrace more reciprocal and much richer relationships among the agents (e.g., sharing grazing resources) by allowing them more complex ways of interacting with each other. The spatio-temporal variability of grazing resources in the environment can be manipulated more broadly for examining its impact on the resource access of the agents. Perhaps, the most pressing extension is making the model's underlying ecological dynamics more realistic as well as more diverse. Here, the model can greatly benefit from a recent trend in rangeland ecology and pastoralism research: a growing body of research based on spatially as well as temporally fine-grained data on rangeland conditions, especially those derived from satellite imagery (Booth \& Tueller, 2003; Egeru, 2014; Miller, 2015; Ruelland, Levavasseur, \& Tribotté, 2010; Tueller, 1989). By fully employing these spatiotemporal data, the abstract and stylized aspects of the model can fruitfully be replaced with more data-driven dynamics.

\section{Acknowledgements}

The author wishes to thank Heinrich Nax and Stefano Balietti for their extensive feedback. Yutaka Arimoto, Karsten Donnay, Isabel Günther, Souknilanh Keola, Laura Metzger, Lloyd Sanders, Jan Schüpbach, Joeri Smits, Kazushi Takahashi and Shinichi Takeuchi contributed useful comments and suggestions on various occasions.

The Japan Society for the Promotion of Science (JSPS) provided valuable financial support (JSPS KAKENHI; Grant 24243023, 24730139, 26-9525 and 15KT0137) during the preparation of this article. The author also acknowledges support by the European Commission through the ERC Advanced Investigator Grant 'Momentum' (Grant 324247).

\section{References}

Adriansen, H. K. (2008). Understanding pastoral mobility: the case of Senegalese Fulani. Geographical Journal, 174(3), 207-222. http://dx.doi.org/10.1111/j.1475-4959.2008.00278.x

Adriansen, H. K., \& Nielsen, T. T. (2005). The geography of pastoral mobility: A spatio-temporal analysis of GPS data from Sahelian Senegal. GeoJournal, 64(3), 177-188. http://dx.doi.org/10.1007/s10708-005-5646-y

African Union [AU]. (2010). Policy framework for pastoralism in Africa: Securing, protecting and improving the lives, livelihoods and rights of pastoralist communities. Retrieved from Addis Ababa, Ethiopia: $\mathrm{http} / / /$ rea.au.int/en/content/policy-framework-pastoralism-africa-securing-protecting-and-improving-lives-li velihoods-and-

Axelrod, R. M. (1997). The complexity of cooperation : agent-based models of competition and collaboration. Princeton, N.J.: Princeton University Press.

Bassett, T. J. (1986). Fulani Herd Movements. Geographical Review, 76(3), 233-248. http://dx.doi.org/10.2307/214143

Bassett, T., \& Turner, M. (2007). Sudden shift or migratory drift? FulBe herd movements to the Sudano-Guinean region of West Africa. Human Ecology, 35(1), 33-49. http://dx.doi.org/10.1007/s10745-006-9067-4

Baxter, P. T. W. (1972). Absence makes the heart grow fonder: Some suggestions why witchcraft accusations are rare among East African pastoralists. In M. Gluckman (Ed.), Allocation of Responsibility (pp. 163-191). Manchester: Manchester University Press.

Behnke, R. H. (1999). Stock movement and range management in a Himba community in north-western Namibia. In M. Niamir-Fuller (Ed.), Managing mobility in African rangelands: The legitimization of transhumance (pp. 184-216). S.l. London: Food and Agriculture Organization of the United Nations : Beijer International Institute of Ecological Economics ; IT Publications.

Behnke, R. H., Scoones, I., \& Kerven, C. (1993). Range ecology at disequilibrium: New models of natural variability and pastoral adaptation in African savannas. London: Overseas Development Institute. 
Boone, C. (2014). Property and political order in Africa: Land rights and the structure of politics. New York: Cambridge University Press.

Boone, R. (2005). Quantifying changes in vegetation in shrinking grazing areas in Africa. Conservation and Society, 3(1), 150-173.

Boone, R. B., \& BurnSilver, S. B. (2002). Integrated assessment results to support policy decisions in Ngorongoro Conservation Area, Tanzania. In Report from the POLEYC project to the global livestock collaborative research support program. California: University of California, Davis.

Booth, D. T., \& Tueller, P. T. (2003). Rangeland monitoring using remote sensing. Arid Land Research and Management, 17(4), 455-467. http://dx.doi.org/10.1080/713936105

Butt, B. (2010). Pastoral resource access and utilization: Quantifying the spatial and temporal relationships between livestock mobility, density and biomass availability in southern Kenya. Land Degradation \& Development, 21(6), 520-539. http://dx.doi.org/10.1002/ldr.989

Catley, A., \& Aklilu, Y. (2013). Moving up or moving out? Commercialization, growth and destitution in pastoralist areas. In I. Scoones, A. Catley, \& J. Lind (Eds.), Pastoralism and development in Africa : dynamic change at the margins (pp. 85-97). Abingdon, Oxon ; New York, N.Y.: Routledge.

Coppolillo, P. B. (2000). The Landscape ecology of pastoral herding: Spatial analysis of land use and livestock production in East Africa. Human Ecology, 28(4), 527-560. http://dx.doi.org/10.1023/A:1026435714109

Coppolillo, P. B. (2001). Central-place analysis and modeling of landscape-scale resource use in an East African agropastoral system. Landscape Ecology, 16(3), 205-219. http://dx.doi.org/10.1023/A:1011148503303

Degteva, A., \& Nellemann, C. (2013). Nenets migration in the landscape: impacts of industrial development in Yamal peninsula, Russia. Pastoralism: Research, Policy and Practice, 3(1), 15.

Dong, S., Wen, L., Liu, S., Zhang, X., Lassoie, J. P., Yi, S., . . . Li, Y. (2011). Vulnerability of worldwide pastoralism to Global changes and interdisciplinary strategies for sustainable pastoralism. Ecology and Society, 16(2).

Dyson-Hudson, R., \& Smith, E. A. (1978). Human territoriality: An ecological reassessment. American Anthropologist, 80(1), 21-41. http://dx.doi.org/10.2307/673509

Egeru, A., Wasonga, O., Kyagulanyi, J., Majaliwa, G., MacOpiyo, L., \& Mburu, J. (2014). Spatio-temporal dynamics of forage and land cover changes in Karamoja sub-region, Uganda. Pastoralism: Research, Policy and Practice, 4(1), 6.

Ellis, J., \& Swift, D. (1988). Stability of African pastoral ecosystems: Alternate paradigms and implications for development. Journal of Range Management, 41(6), 450-459. http://dx.doi.org/10.2307/3899515

Ermon, S., Xue, Y., Toth, R., Dilkina, B., Bernstein, R., Clark, P., . . Gomes, C. P. (2015). Learning large-scale dynamic discrete choice models of spatio-temporal preferences with application to migratory pastoralism in East Africa. Paper presented at the the Twenty-Ninth AAAI (Association for the Advancement of Artificial Intelligence) Conference on Artificial Intelligence.

Evans-Pritchard, E. E. (1940). The Nuer, a description of the modes of livelihood and political institutions of a Nilotic people. Oxford,: At the Clarendon press.

Food and Agriculture Organization [FAO]. (2016). Pastoralist Knowledge Hub. Retrieved from http://www.fao.org/pastoralist-knowledge-hub/en/

Fratkin, E. M., \& Roth, E. A. (2004). As pastoralists settle : social, health, and economic consequences of the pastoral sedentarization in Marsabit District, Kenya. New York: Kluwer Academic/Plenum Publishers.

Galaty, J. G. (2013). Land grabbing in the Eastern African rangelands. In I. Scoones, A. Catley, \& J. Lind (Eds.), Pastoralism and development in Africa: Dynamic change at the margins (pp. 143-153). Abingdon, Oxon ; New York, N.Y.: Routledge.

Golecha, R., \& Gan, J. (2016). Effects of corn stover year-to-year supply variability and market structure on biomass utilization and cost. Renewable and Sustainable Energy Reviews, 57, 34-44. http://dx.doi.org/10.1016/j.rser.2015.12.075

Helbing, D. (2012). Social self-organization: agent-based simulations and experiments to study emergent social behavior. Heidelberg: Springer. 
Holland, J. H. (1992). Adaptation in natural and artificial systems: An introductory analysis with applications to biology, control, and artificial intelligence (1st MIT Press ed.). Cambridge, Mass.: MIT Press.

Homewood, K. (2008). Ecology of African pastoralist societies. Oxford; Athens, OH; Pretoria: James Currey; Ohio University Press; Unisa Press.

Kahsay, G. A., \& Hansen, L. G. (2016). The effect of climate change and adaptation policy on agricultural production in Eastern Africa. Ecological Economics, 121, 54-64. http://dx.doi.org/10.1016/j.ecolecon.2015.11.016

Lane, C., \& Moorehead, R. (1994). New directions in rangeland and resource tenure and policy. In I. Scoones (Ed.), Living with uncertainty: new directions in pastoral development in Africa (pp. 116-133). London: Intermediate Technology Publications.

Lund, C. (2008). Local politics and the dynamics of property in Africa. New York: Cambridge University Press.

Mace, R. (1991). Overgrazing overstated. Nature, 349(6307), 280-281.

MacOpiyo, L. A. (2005). Spatially explicit, individual-based modelling of pastoralists' mobility in the rangelands of east Africa. (Doctoral dissertation), Texas A\&M University. Retrieved from http://oaktrust.library.tamu.edu/handle/1969.1/2631

McPeak, J. G., Little, P. D., \& Doss, C. R. (2012). Risk and social change in an African rural economy: Livelihoods in pastoralist communities. London; New York: Routledge.

Miller, B. W. (2015). Using geospatial analysis to assess the influence of land-use change and conservation on pastoralist access to drought resources. Nomadic Peoples, 19(1), 120-145. http://dx.doi.org/10.3197/np.2015.190108

Moritz, M., Hamilton, I. M., Yoak, A. J., Scholte, P., Cronley, J., Maddock, P., \& Pi, H. (2015). Simple movement rules result in ideal free distribution of mobile pastoralists. Ecological Modelling, 305(0), 54-63. http://dx.doi.org/10.1016/j.ecolmodel.2015.03.010

Moritz, M., Larisa Catherine, B., Drent, A., Kari, S., Mouhaman, A., \& Scholte, P. (2013). Rangeland governance in an open system: Protecting transhumance corridors in the Far North Province of Cameroon. Pastoralism: Research, Policy and Practice, 3(1), 26.

Moritz, M., Soma, E., Scholte, P., Xiao, N., Taylor, L., Juran, T., \& Kari, S. (2010). An integrated approach to modeling grazing pressure in pastoral systems: The Case of the Logone Floodplain (Cameroon). Human Ecology, 38(6), 775-789. http://dx.doi.org/10.1007/s10745-010-9361-z

Musembi, C. N., \& Kameri-Mbote, P. (2013). Mobility, marginality and tenure transformation in Kenya: Explorations of community property rights in law and practice. Nomadic Peoples, 17(1), 5-32. http://dx.doi.org/10.3167/np.2013.170102

Niamir-Fuller, M. (1999). Managing mobility in African rangelands: The legitimization of transhumance. S.1. London: Food and Agriculture Organization of the United Nations: Beijer International Institute of Ecological Economics; IT Publications.

Oba, G., \& Kaitira, L. M. (2006). Herder knowledge of landscape assessments in arid rangelands in northern Tanzania. Journal of Arid Environments, 66(1), 168-186. http://dx.doi.org/10.1016/j.jaridenv.2005.10.020

Oba, G., Stenseth, N. C., \& Lusigi, W. J. (2000). New perspectives on sustainable grazing management in arid zones of Sub-Saharan Africa. BioScience, 50(1), 35-51. http://dx.doi.org/10.1641/0006-3568

Oba, G., Weladji, R. B., Lusigi, W. J., \& Stenseth, N. C. (2003). Scale-dependent effects of grazing on rangeland degradation in northern Kenya: a test of equilibrium and non-equilibrium hypotheses. Land Degradation \& Development, 14(1), 83-94. http://dx.doi.org/10.1002/ldr.524

Opiyo, F., Wasonga, O. V., \& Nyangito, M. M. (2014). Measuring household vulnerability to climate-induced stresses in pastoral rangelands of Kenya: Implications for resilience programming. Pastoralism: Research, Policy and Practice, 4(1), 10. http://dx.doi.org/10.1186/s13570-014-0010-9

Pickup, G., \& Chewings, V. H. (1988). Estimating the distribution of grazing and patterns of cattle movement in a large arid zone paddock: an approach using animal distribution models and Landsat imagery. International Journal of Remote Sensing, 9(9), 1469-1490. http://dx.doi.org/10.1080/01431168808954953

Ray, D. K., Gerber, J. S., MacDonald, G. K., \& West, P. C. (2015). Climate variation explains a third of global crop yield variability. Nature Communications, 6. http://dx.doi.org/10.1038/ncomms6989 
Rice, W. F. (1975). Patterns in geography Book two. London: Longman.

Ruelland, D., Levavasseur, F., \& Tribotté, A. (2010). Patterns and dynamics of land-cover changes since the 1960s over three experimental areas in Mali. International Journal of Applied Earth Observation and Geoinformation, 12, Supplement 1(0), S11-S17. http://dx.doi.org/10.1016/j.jag.2009.10.006

Sandford, S. (1983). Management of pastoral development in the Third World. Chichester West Sussex ; New York: Wiley.

Sato, S. (1980). Pastoral movements and the subsistence unit of the Rendille of Northern Kenya : with special reference to camel ecology. Senri Ethnological Studies, 6, 1-78.

Sayama, H. (2013). PyCX: A Python-based simulation code repository for complex systems education. Complex Adaptive Systems Modeling, 1(1), 2.

Sayama, H. (2015). Introduction to the Modeling and Analysis of Complex Systems. Geneseo, NY: Open SUNY Textbooks.

Schareika, N. (2003). Know to move, move to know: Ecological knowledge and herd movement strategies among the Wodaabe of Southeastern Niger. Rome: FAO Inter-Departmental Working Group on Biological Diversity for Food and Agriculture.

Scoones, I. (1994). Living with uncertainty: New directions in pastoral development in Africa (Repr. 1996 ed.). London: Intermediate Technology Publications.

Scoones, I. (1995). Exploiting heterogeneity:habitat use by cattle in dryland Zimbabwe. Journal of Arid Environments, 29(2), 221-237. http://dx.doi.org/10.1016/S0140-1963(05)80092-8

Scoones, I. (1999). Ecological dynamics and grazing-resource tenure: A case study from Zimbabwe. In M. Niamir-Fuller (Ed.), Managing mobility in African rangelands: The legitimization of transhumance (pp. 217-235). S.l. London: Food and Agriculture Organization of the United Nations: Beijer International Institute of Ecological Economics; IT Publications.

Scoones, I., \& Graham, O. (1994). New directions for pastoral development in Africa. Development in Practice, 4(3), 188-198. http://dx.doi.org/10.1080/096145249100077821

Scoones, I., Catley, A., \& Lind, J. (2013). Pastoralism and development in Africa: Dynamic change at the margins (1st ed.). Abingdon, Oxon ; New York, N.Y.: Routledge.

Spencer, P. (1973). Nomads in alliance; symbiosis and growth among the Rendille and Samburu of Kenya. London, New York,: Oxford University Press for the School of Oriental and African Studies.

Stenning, D. J. (1957). Transhumance, migratory drift, migration; patterns of pastoral Fulani nomadism. The Journal of the Royal Anthropological Institute of Great Britain and Ireland, 87(1), 57-73. http://dx.doi.org/10.2307/2843971

Sulieman, H., \& Ahmed, A. G. (2013). Monitoring changes in pastoral resources in eastern Sudan: A synthesis of remote sensing and local knowledge. Pastoralism: Research, Policy and Practice, 3(1), 22.

Thompson, W., Meyer, S., \& Westhoff, P. (2009). How does petroleum price and corn yield volatility affect ethanol markets with and without an ethanol use mandate? Energy Policy, 37(2), 745-749. http://dx.doi.org/10.1016/j.enpol.2008.08.035

Thornton, P. K., BurnSilver, S. B., Boone, R. B., \& Galvin, K. A. (2006). Modelling the impacts of group ranch subdivision on agro-pastoral households in Kajiado, Kenya. Agricultural Systems, 87(3), 331-356. http://dx.doi.org/10.1016/j.agsy.2005.03.001

Toth, R. (2015). Traps and thresholds in pastoralist mobility. American Journal of Agricultural Economics, 97(1), 315-332. http://dx.doi.org/10.1093/ajae/aau064

Tueller, P. T. (1989). Remote sensing technology for rangeland management applications. Journal of Range Management, 42(6), 442-453.

Turner, M. D. (1999). The role of social networks, indefinite boundaries and political bargaining in maintaining the ecological and economic resilience of the transhumance systems of Sudano-Sahelian West Africa. In M. Niamir-Fuller (Ed.), Managing mobility in African rangelands: The legitimization of transhumance (pp. 97-123). S.l. London: Food and Agriculture Organization of the United Nations : Beijer International Institute of Ecological Economics ; IT Publications. 
Turner, M. D., \& Hiernaux, P. (2002). The use of herders' accounts to map livestock activities across agropastoral landscapes in Semi-Arid Africa. Landscape Ecology, 17(5), $367-385$. http://dx.doi.org/10.1023/A:1021238208019

Urban, D., Roberts, M. J., Schlenker, W., \& Lobell, D. B. (2012). Projected temperature changes indicate significant increase in interannual variability of U.S. maize yields. Climatic Change, 112(2), 525-533. http://dx.doi.org/10.1007/s10584-012-0428-2

Wheeler, T., \& von Braun, J. (2013). Climate Change Impacts on Global Food Security. Science, 341(6145), 508-513. http://dx.doi.org/10.1126/science.1239402

\section{Copyrights}

Copyright for this article is retained by the author(s), with first publication rights granted to the journal.

This is an open-access article distributed under the terms and conditions of the Creative Commons Attribution license (http://creativecommons.org/licenses/by/3.0/). 